\title{
LA CONSTRUCCION DE LAS IDENTIDADES FEMENINAS MISAK ${ }^{*}$
}

\author{
Nancy Yenny Velasco Guasamalli
}

\begin{abstract}
Resumen
Muchos son los estudios sobre comunidades indígenas durante los últimos años del siglo XX. Esto obedece al interés desde diferentes disciplinas de las ciencias sociales de buscar nuevas líneas de investigación que vinculen nuevos sujetos poco trabajados. En este sentido un trabajo realizado durante el 2008 en el proyecto "Sexualidades y feminidades contemporáneas de mujeres negras e indígenas" generó la necesidad de ahondar más sobre este tema. Por ello, continuado, lo retomo como trabajo de maestría en donde desde una mirada étnica se pretende mostrar como las mujeres indígenas Misak construyen su feminidad desde tres elementos: un vínculo hacia la madre tierra, otro hacia los tejidos y otro hacia el fogón.
\end{abstract}

Palabras claves: Feminidades, identidades, étnicas, guambia, Misak

\section{Abstract}

There are many studies on the indigenous communities during the last years of the 20th century. This reflects the interest of the other disciplines of social sciences to seek new research lines linking new subjects little work in this sense and this is work done during 2008 in the "contemporary sexuality and femininity of black women and indigenous " generated of need to move on the issue and continuing on, I return as master's degree work and from an ethnic look is to show how indigenous women MISAK construct their femininity from three types of links, link to the Mother Earth, link to the tissues, and the link to the fire

Key words: Femininity, identities, ethnic, guambia, Misak

\section{Introducción}

La lucha de los pueblos indígenas por el reconocimiento de sus derechos y la reexistencia ${ }^{1}$ de su cultura es incesante. O seguramente será así, hasta que ese reconocimiento - que hasta ahora es simbólico - de "un estado pluriétnico y multicultural" genere un verdadero significado. En cuanto a esta política indígena, el pueblo Misak $^{2}$ ejerce grandes tensiones, llevando vivas sus prácticas culturales.

\footnotetext{
* Artículo tipo 2, de reflexión según clasificación de Colciencias. Hace parte de la tesis de grado que se encuentra en realización para optar el título de Maestría en Historia de la Universidad del Valle.

*** Licenciada en Historia, Universidad del Valle; Estudiante de Maestría en Historia; integrante del Grupo de investigación Región, Universidad del Valle. E-mail: yennyvel@gmail.com

${ }^{1}$ Concepto acuñado por el pueblo Misak que aplica a diferencia del concepto resistir ya que este sugiere un enfrentamiento hacia el otro. Entre tanto re- existencia ya que existimos y luchamos es por seguir existiendo.

${ }^{2}$ Conocido como Pueblo Guambiano.
} 
Sin embargo, mi iniciativa en el siguiente articulo no está ligada al marco por ahora jurídico, sino hacia el análisis de cómo la comunidad y en particular las mujeres, son parte altamente activa de esa re-existencia como sujetas históricas que aportan en la conservación de la identidad cultural Misak. Ellas participan positivamente de varias maneras: son administradoras de la familia, al ser la columna vertebral de la educación del pueblo Misak, apoyan e impulsan la producción agrícola contribuyendo a la economía propia, y entre otras cosas comercializan artesanías o productos dependiendo de las necesidades. Es esta cotidianidad de colaboración la que influye tenazmente dentro de la construcción de la identidad femenina Misak. No obstante, desde una óptica de género, es notorio que en muchas ocasiones los discursos tanto masculinos como femeninos tienden a subvalorar a la mujer Misak (no desde su trabajo físico sino desde su capacidad intelectual).

Para este gran propósito de trabajo investigativo, es necesario aclarar cuatro elementos iniciales, primero: no lograré, en este corto trabajo desarrollar a gran escala lo planteado anteriormente ya que representa una búsqueda a una construcción mayor. Segundo, inicialmente realizaré un panorama del contexto geográfico donde se desarrollan estas feminidades Misak. En tercer lugar, describiré la metodología acorde a utilizar y cuarto, mostraré sólo algunas de las categorías en este análisis utilizadas así como su aplicabilidad en el contexto Misak.

Aclarado lo anterior, continuaré con el segundo elemento que tiene que ver con la ubicación geográfica del resguardo de Guambía, cuyo territorio está ubicado en el municipio de Silvia, departamento del Cauca a 40 minutos de Popayán, la capital. Su clima es frío, lo cual reverdece hermosas montañas que rodean el paisaje. Como podemos observar en el mapa, el municipio de Silvia es, en su inmensa mayoría, territorio indígena. Está conformado por territorio Guambiano, Nasa, Quizqueño y Ambalueño (estos dos últimos en su mayoría producto de la mezcla entre Misak y Nasas). El casco urbano es pequeño pero rico en su diversidad étnica y cultural convirtiéndolo en gran atractivo turístico, ya que allí se concentran cuatro etnias indígenas, además de campesinos y mestizos.

La economía y producción del pueblo Misak, se basa en la producción de consumo y distribución familiar, como unidad básica del trabajo en la comunidad, es decir que el principal factor de producción es la tierra, a la cual están articuladas las actividades productivas agrícolas y de ganadería. En algunos casos, la piscicultura, el comercio y artesanías, son servicios particularmente vendidos por el cabildo, así como las prendas básicas que tejen las mujeres Misak.

La movilidad espacial del Misak no se limita a Silvia, ya que por sus prácticas agropecuarias y en el ejercicio de su comercialización debe movilizarse hacia ciudades como Cali y preferiblemente hacia Popayán. Esta labor de vender los 
productos es realizada en la mayoría de los casos por mujeres, en colaboración de los hombres.

Un tercer elemento dentro de la descripción de este trabajo, es la metodología, la cual se basó en la realización de entrevistas biográficas en profundidad, a mujeres Misak del resguardo de Guambía, en total seis, y un hombre, todas ellas, levantadas en el 2008. Estas entrevistas permiten visualizar roles tanto femeninos como masculinos que posibilitan relacionar elementos cotidianos y conductas en ejercicio de su socialización y empoderamiento dentro del espacio privado, con la actividad de producción de su identidad femenina.

El cuarto elemento, tuvo en cuenta algunas categorías. Las primeras son el género y la identidad y, aunque sólo se da un leve pincelazo de ello, la sexualidad y la violencia de género. El citado inicialmente como categoría, el género, según Scott (Castellanos, 2006) tiene tres partes: primero "un elemento constitutivo de las relaciones sociales que se basa en las diferencias que distinguen los sexos"; segundo, el género es "una forma primaria de relaciones significantes de poder", a la vez que "el campo primario dentro del cual o por medio del cual se articula el poder"; y tercero "es el conjunto de saberes sociales (creencias, discursos, instituciones y practicas) sobre las diferencias entre los sexos".

Es entonces, el elemento final mencionado, un eje transversal de todas las representaciones sociales de la mujer Misak dentro de la cultura y esta categoría permite, no sólo indagar para comprender sino visibilizar, para así deconstruir las relaciones desiguales de poder que están en la base de las estructuras sociales así como en las estructuras mismas del psiquismo de los hombres y de las mujeres, como uno de los dispositivos de la lógica de la dominación. Y esta dominación es entendida desde la sexualidad como un elemento constitutivo de poder.

En la segunda categoría, se consideró un concepto de identidad que permitió buscar esa construcción de las identidades femeninas Misak, ya que en estos tiempos cuando el mundo cambia rápidamente $y$, hombres y mujeres se debaten tensionalmente entre la globalización, la segmentación cultural y el surgimiento de distintas formas de individualismo como elementos que parecen anunciar el escenario de estos tiempos posmodernos, la pregunta sobre la identidad cobra relevancia en la tarea de repensar los procesos de subjetivación y comprender las transformaciones de la identidad genérica, por lo que resulta imprescindible, a la hora actual, estudiar las formas en que se construye el sentido y la significación sociosimbólica que hombres y mujeres tienen de sí mismos/as como percepción fundante de su personalidad en interacción con la cultura.

En este sentido es importante buscar también esa identidad individual, ya que permite la constitución del ser social en cuanto individuo. $Y$ la identidad colectiva 
entendida en relación con la pertenencia a un grupo étnico Al respecto, Kwame Anthony Appiah dice:

El uso contemporáneo de la palabra 'identidad' para referirse a características de las personas tales como la raza, la etnia, la nacionalidad, el género, la religión o la sexualidad adquirió preeminencia por primera vez en la psicología social de la década de 1950, particularmente en los trabajos de Eric Erikson y Alvin Gouldner. Este uso del término refleja la convicción de que la identidad de cada persona -en el sentido más antiguo de quién se es en verdad- está profundamente imbuida en esas características sociales. Y el predominio creciente de esta convicción es un hecho de la vida contemporánea.

Es así como la identidad debe verse como una construcción cultural, pues como menciona Laclau, al hablar hoy de identidades, por lo general se piensa en ellas no como únicas y fijas, sino como múltiples y dinámicas.

\section{La Voz de la Mujer Misak}

Es necesario profundizar sobre la situación histórica y actual de la mujer Misak. Con su voz, ellas pueden suministrar una idea exacta de la vida familiar de los mayores, del impacto de los cambios ocurridos y de los problemas causados por esos cambios, especialmente en sus vidas. Por eso anotamos a continuación sus propias impresiones, resaltando el valor cultural y moral de sus opiniones, que aclaran muchas de las informaciones y análisis hechos en los apartados siguientes ${ }^{3}$.

\section{La Situación Ancestral}

La Ishuk Misak se caracteriza por ser muy laboriosa ${ }^{4}$, responsable de la educación de sus hijos, logrando un gran aporte a la pervivencia y re-existencia de la vida del territorio Misak. Sin embargo, estas cualidades no la hacen ajena a la violencia de género y a elementos discriminatorios dentro de la comunidad Misak, en este sentido se plantea:

A pesar de poseer estas virtudes ha sido maltratada física y psicológicamente por parte del hombre, tal vez, este comportamiento haya sido heredado del invasor español. Ella no podía expresar con libertad sus sentimientos por miedo a ser agredida. A pesar de esto, siempre ha sido la base fundamental en la educación y formación de los niños y niñas, por lo tanto, cuando una mujer cometía un error era señalada por mucho tiempo; y todavía hoy debe ser un ejemplo de rectitud. (Memorias encuentros de mujeres Misak 2005).

\footnotetext{
${ }^{3}$ Arch. Del Cabildo Indígena de Guambia, Resumen tomado de encuentros de mujeres Misak “, Sierra Morena, 30 de septiembre y 1 de octubre de 2005. Memorias y recuentos”.

${ }^{4}$ Por estudios realizados se ha demostrado que mientras el hombre realiza 50 oficios la mujer realiza 80 oficios
} 
Igualmente, su vinculación en la educación es un elemento cohibido y negado por parte de sus padres, porque anteriormente se tenía la concepción de que ésta influía de manera negativa en el buen desarrollo como mujer:

Desde su nacimiento, la mujer fue discriminada por sus padres al prohibírsele la educación formal con el argumento que se iban a volver perezosas, o se iban a olvidar de los innumerables trabajos que debían realizar en las labores cotidianas. Por eso, a las niñas solamente las enviaban a la escuela por dos años para que no se volvieran perezosas en las labores de la cocina y el campo (Tomado del plan de vida misak).

En el primer año me entraron, mi mamá, cuando se murió mi mamá, ya... había acabado el primero, ya después iba a entrar en segundo, ya cuando estaba en segundo año, se murió mi mamá, ya de ahí ya me sacaron. "Que en la escuela son perezosos, no hacen nada", ya me sacaron las hermanas, no me quisieron gastar más, ya iba a pasar a tercero y no, en segundo año no más me sacaron (Entrevista a Doña Julia, marzo de 2008).

Sin embargo se resalta su formación ligada al $\mathrm{Na}$ chak $^{5}$ donde surge la educación propia Guambiana, como centro umbilical de la identidad, ya que simboliza el vínculo con el territorio y desde donde se nutre el ideal de ser misak- misak. Es en el fogón donde se estructura el pensamiento desde el conocimiento impartido por los mayores. Y por ello, según la tradición, al recién nacido se le enterraba el ombligo al lado derecho del fogón, como símbolo de unión con su territorio y su familia, así desde donde se encontrare, estará ligado:

... recibían la educación que le brindaba la familia, el papá y la mamá, y se trabajaba en tres sitios: en el campo, aprendiendo a trabajar la tierra; en la cocina (NakChak), mientras se preparaban los alimentos; y en los momentos libres, cuando los mayores nos sentaban a su lado para enseñarnos a hacer los hilados, las mochilas, los chumbes. Pero primero nos enseñaban a trabajar la tierra y luego a elaborar los trabajos manuales, las cosas que necesitamos. Además, nos enseñaban que las mujeres no debemos ser dependientes: por eso desde los 10 años nos daban los materiales necesarios para que comenzáramos a tejer el anaco o la ruana. Porque para eso estaban las manos: o si no, debíamos colaborar a otras mujeres que solo se dedicaban al trabajo de cultivar la tierra. Así, cuando aprendíamos el arte de tejer, trabajar, cocinar, era un principio de una persona de preparación para después recibir un ingreso económico con lo cual solventábamos las necesidades (Tomado del plan de vida Misak).

En este sentido, la responsabilidad de la educación hacía parte de la gran familia, conformada por los padres, abuelos, tíos, tías y allegados, quienes tenían y se sentían con derecho a educar a sus allegados, así estuvieran los padres de familia

\footnotetext{
${ }^{5}$ Palabra que significa Fogón en lengua Misak.
} 
o no. Además de la enseñanza de los mayores existía el compromiso de que cualquier falta o problema que se presentara, se dialogaba en familia, o con los taitas mayores, sin poner en conocimiento al Cabildo, porque se consideraba que la autoridad se iniciaba en la familia, y hacer esto es una forma negativa de presentar la imagen de la familia ante la comunidad. Los mayores daban consejo sobre la responsabilidad de concebir un hijo, mientras los jóvenes debían tener claro si lo deseaban o no, teniendo en cuenta su capacidad para sostenerlo y educarlo en la vida de pareja. También para que supieran tomar una decisión correcta enseñaban a hablar con respeto y con humildad:

Para las mujeres visitar a los padres, después del matrimonio, solo se hacía por momentos; porque se sentían prohibidas porque ellas debían permanecer más tiempo donde el esposo. Esa era la condición: que no podían regresar cuando quisieran donde ellos, por considerarse al esposo como el segundo padre y la esposa la segunda madre (Tomado del plan de vida Misak).

\section{La Mujer Misak de Hoy}

Mucha es la crítica que se ha hecho con respecto a la situación de la mujer actual, realizada esta por la comunidad tradicional la cual argumenta:

La situación de la mujer ha cambiado, en algunos aspectos, como en la crianza de sus hijos. Se ha olvidado un poco la manera de orientar de acuerdo a los usos y costumbres de los mayores. Una de las causas es que hay matrimonios de parejas muy jóvenes, lo cual incide negativamente en la formación y educación de sus hijos, por su falta de experiencia y tradición. Esto se puede ver en la pérdida de valores de los que se ha hablado; pero también de saberes propios de la mujer, como el hilar la lana para los vestidos y la práctica de rituales durante todo el ciclo de vida. También es conocido que la mujer en estos últimos tiempos ha tenido la oportunidad de educarse formalmente. Eso de haberse preparado académicamente también es valioso, porque le ha permitido ocupar cargos importantes dentro de la vida social de la comunidad, como alguaciles, secretarias, alcaldesas, educadoras y últimamente el cargo de vicegobernadora. Cargos que han desempeñado responsable y éticamente. Pero, además, ya no es tan maltratada por parte del hombre (Tomado del plan de vida Misak).

Sin embargo, ahora, hay algunas jóvenes Misak que no han desarrollado esa idea de identificarse como laboriosas, porque se visten de civil y andan con las manos cruzadas, o con el sobrero en la mano, llevando radio, o jugando. Se está perdiendo ese sentir integral de identificarnos como verdaderas mujeres capaces de asumir y realizar las tareas más complejas en bienestar de la familia y la colectividad. También pasa que al salir y regresar de las ciudades algunas mujeres se han dejado influenciar de las ideas occidentales; es decir, con formas y estilos de vida ajenos. Por eso no quieren pensar, vestir y hacer los trabajos del misak-misak; pero algunas han mantenido las costumbres, así estén donde estén (Tomado del plan de vida Misak). 
No obstante, esta crítica de los mayores de la comunidad se ha dado bajo la pérdida de identidad, ligada a unas dinámicas globales que también influyen dentro de las y los jóvenes a través de los medios masivos de comunicación. Y son criticas que obvian elementos relacionados con las distintas iniciativas de las mayoras de generar resistencia frente a una practicas de dominación históricamente construidas con respecto a los roles dentro del hogar. De esta manera la mujer de hoy está repensando el sentido de su ser como mujer, una mujer que puede abrirse hacia otros espacios públicos, como la educación, el ámbito político y ser elegida además en cargos administrativos.

La joven de hoy habla de amigos y se reúnen con ellos, es decir con los muchachos; pero anteriormente para nosotras era como si no existieran, porque teníamos que salir y andar atrás de ellos. Ahora la mujer es compañera del hombre, ayuda a pensar, a hacer y tener de las cosas. La mujer es más fuerte y capaz de sobresalir frente a las adversidades de la vida.

\section{Ser Mujer Misak}

Hasta aquí se puede evidenciar que la mujer de hoy es heredera de una resistencia iniciada por sus abuelas y mamas ${ }^{6}$ frente a la dominación masculina, mayoritariamente permisiva, heredada de prácticas coloniales españolas. Prácticas de un falocentrismo europeo, que se fueron fundiendo y confundiendo dentro de los usos y costumbres de la cultura misak.

Estas prácticas no se evidencian o están en oposición dentro del discurso de la cosmovisión del ser misak, ya que la mujer se valora como eje principal de la cultura, es vista como una deidad y esto se puede constatar en el mito de origen del pueblo Guambiano:

Los orígenes del pueblo Guambiano, empiezan con una pareja: uno se llama Kallim y el otro Pishimisak. El kallin al principio del tiempo le dijo al pishimisak: juntémonos y formemos la pareja; entonces el pishimisak respondió, si hay equilibrio y armonía formaremos la pareja.

Volvió a hablar nuevamente el Kallim y le dijo: yo soy tata (líder) pero a la vez soy taita (padre), conozco todos los trabajos y las mingas de los Namuy Misak, conozco toda la variedad de plantas existentes afirmo Kallim al Pishimisak; entonces Pishimisak respondió yo seré el cordón umbilical como el mejicano (fruto parecido a una sandia). Así le respondió Pishimisak al Kallim yo hablo de equilibrio y armonía para la existencia del hombre (y mujer) Guambiano. Luego volvió a responder Pishimisak: yo soy mama (como los mamos kogui) Dominga y vivo entre las plantas del páramo y a la vez soy madre de las aguas del territorio Guambiano.

\footnotetext{
${ }^{6}$ Mama, concepto que se le adjudica a las mayoras en cosmovisión pensamiento y sabiduría dentro de la comunidad misak.
} 
Pishimisak en la cosmovisión guambiana es el todo, es la principal deidad que trasciende todas las cosas y es la esencia misma de las cosas. Es femenino y algunas veces asexuado. En este sentido sus descendientes femeninas construyen uno de los cuatro pilares del ser Misak ${ }^{7}$, el nak chak (o fogón), desde donde se une y da vida a la familia y con ella a la comunidad.

Es la mujer la que teje los hilos de la comunidad, en sus manos el huso es un elemento casi primordial que le da un estatus de trabajadora al tener siempre las manos ocupadas. Precisamente, el tejido es otra de las características de la feminidad Misak. Desde la infancia se les inicia en el tejido, generando una especie de graduación al elaborar ella misma su anaco ${ }^{8}$. Al terminarlo, está lista para contraer matrimonio ya que igualmente podrá elaborar la ruana de su futuro esposo.

En el tejido hay una expresión del sentir, del arte, que involucra creatividad e ingenio. Todo lo anterior está plasmado y geométricamente delineado, incluso desde las mochilas se pueden generar pedagogías vinculadas a la enseñanza de la geometría desde otras instancias.

Y es aquí donde el discurso desde lo femenino Misak debe replantear la práctica ya que por un lado, se evidencia como plantea Beauvoir (1949), que "la mujer se determina y se diferencia con relación al hombre, y no éste con relación a ella; la mujer es lo inesencial frente a lo esencial. Él es el sujeto, él es lo absoluto; ella es lo Otro". Así algunas mujeres misak se definen desde un rol de sumisión, con el deber solamente biológico, al ser procreadoras, abnegadas a la crianza de sus hijos e hijas adscritas completamente a lo privado de sus hogares, con una casi nula presencia en el campo político.

Tienen ellas en sus manos las primeras bases de las enseñanzas en la construcción de la identidad Misak desde el fogón, la tierra y el tejido. Y esa función es heredada del pishimisak en este sentido deberían ser ellas respetadas, valoradas y su voz escuchada a la hora de edificar el futuro de la comunidad.

\footnotetext{
${ }^{7}$ De acuerdo con la cosmogonía heredada de nuestros mayores las raíces ( $\operatorname{sr} \theta l$ ) o factores que han determinado nuestra cultura por encima de todo han sido: 1.La ley natural, que algunos llaman de origen, que nos une a todos los seres vivos de la tierra; la única que es imperecedera, inmutable e incambiable, por lo cual exige el máximo respeto. Ella dio nacimiento al hombre, y en este caso a nosotros, los Namuy Misak. 2. El nak chak (o fogón), ya nombrado, que une y da vida a la familia y con ella a la comunidad. 3. La $n \theta-\tilde{n} i$ (pareja), como base de toda unión creadora, de la familia y base de la sociedad. 4. El ellmar $\theta p$ (cultivo) como norma invariable para la subsistencia de los Misak.

${ }^{8}$ Anaco: prenda de vestir de las mujeres Misak que hace referencia a la falda la cual porta granjas que describen la procedencia de la familia.
} 


\section{Roles Femenino y Masculino}

Siendo consecuente con lo anteriormente planteado, la relación individuo sociedad se evidencia a través de los comportamientos, la experiencia de vida y las prácticas sociales. Pero en el ámbito de lo privado, lo femenino y lo masculino implica unos comportamientos que desembocan en una cadena de jerarquías de poder establecidas desde el plano patriarcal dentro de la familia. En así como en la comunidad Misak, el varón cabeza de familia estaría en la cúspide de esa jerarquía, pasando por la madre, luego los hijos hombres y de último, las hijas mujeres.

En este plano, los roles están finamente delineados en la mayoría de los casos, lo cual se observa en los argumentos referidos a los términos de la crianza de los hijos:

En cuanto a la crianza, a la educación... Le toca más a uno, porque los papás están es dispuestos a mandar "haga esto, no haga esto, vaya a esto" pero nunca se sientan con ellos ni, que tiene que andar así, ni que ¿Cómo te fue? ¡Ummjhuu! los hombres... no se si en la cultura mestiza, pero acá hoy en día yo he visto que eso es, solo dejan a las mujeres y más en la escuela uno se da cuenta que, en las reuniones de padres de familia la mayoría de personas que asisten son mamás (Archivo Casa de Justicia del pueblo guambiano).

Estos roles también se evidencian cuando se indaga sobre el jefe del hogar, aunque hay un respeto por enunciar al varón, en la práctica se evidencian otro tipo de circunstancias, que denomina a la mujer en el plano de liderar responsabilidades y habilidades que demuestran su capacidad de autogobernarse dentro de lo privado

Pues acá dicen que son los hombres, pero parece que viéndolo bien parece que son las mujeres jajaja. Por que uno está en la educación de los hijos, uno está haciendo la remesa, uno es el que está pagando que los servicios, así colaborando en todo, entonces como que uno es el que está en todo para que funcione la casa entonces el jefe del hogar pues es uno (Entrevista a Rosa Marzo de 2008).

En el ámbito de lo público se revierten las situaciones de la mujer, ya que se evidencia un ausentismo marcado en los espacios de socialización política como las asambleas del cabildo de índole jurídico. Claro está, que sí hay una presencia, pero de una manera tímida y receptiva y muy pocas veces participativa. Su participación mayoritaria se sigue dando en el ámbito de lo privado, en la cocina. 
El ejercicio de poder no está muy interiorizado en la mujer dentro del ámbito de lo público. Aunque se encuentra una vicegobernadora, Mama Bárbara Muelas, ella tiene a su favor un reconocimiento académico adquirido gracias a la maestría en lingüística que tiene, lo cual le genera cierto estatus. También, en el último periodo electoral fueron elegidas dos concejalas Misak, además de su ocupación en otros cargos administrativos que generan un estatus de poder económico. Y ellas pueden ser un faro a seguir en aras de ese empoderamiento Misak.

De esta manera una de las principales resistencias de las mujeres Misak está ligada a la vinculación de sus hijas a la educación, al ver este medio como un método que las puede proteger de prácticas en las que no están conformes. Por tanto, son ellas las que apoyan tanto económica como moralmente a sus hijas para que terminen sus estudios. Hoy en día es común encontrar a muchas de ellas, dentro de la cocina, en el fogón generando grandes aportes, algunas son universitarias o profesionales otras concejalas, académicas, o amas de casa, que se deben a su comunidad.

En este sentido, también hay algunas dentro de las asambleas, que desean ser y son escuchadas, replanteando con esto nuevas formas de redireccionar la comunidad. Desde ahí están buscando ese trascender, están aportando sus pensares, y aunque se siguen asumiendo como el otro, ya están posicionando su sentir, están mostrando esa libertad autónoma que sólo las limitaba a la esfera privada del hogar.

\section{Mujer Misak y Sexualidad}

Un elemento demarcador de dominación masculina se puede evidenciar cuando se indaga en el marco de la sexualidad. Ya que desde ahí se tejen concepciones con respecto al cuerpo y la mentalidad de hombres y mujeres que otorgan significado a su entorno. Así Córdoba asegura "la sexualidad, al ser un punto de confluencia entre la normatividad social y la acción ética de los individuos, puede contemplarse como una herramienta metodológica privilegiada para el análisis de las oscilaciones en el equilibrio de poder entre los géneros".

Esta categoría permite considerar la violencia de género, como una práctica cultural que es permitida y se promociona a través de los espacios públicos como elemento diferenciador entre la jerarquía antes mencionada. Por lo tanto, es necesario comentar que la violencia doméstica sexual es un problema multidimensional complejo que se ha ido construyendo socioculturalmente a través de un aprendizaje social, enraizado a una lógica de desigualdad de género que reproduce la violencia jerárquica de poder.

Para puntualizar en este sentido son muchas las mujeres Misak que confidencian un maltrato de parte de sus cónyuges, al ser objeto de lesiones físicas y psicológicas, lo que implica no sólo a la mujer sino también a los menores de 
edad. Por lo general, esto ocurre cuando sus esposos están embriagados y llegan de compartir con los demás comuneros en el pueblo.

\begin{abstract}
Bueno yo recuerdo es que cada vez que... mejor dicho un día martes que el no llegara a las seis de la tarde ya uno empezaba a temblar por los maltratos que el podría llegar a hacer, cuando llegara borracho, el siempre llegaba y se dedicaba era así, llegaba tranquilo pero no se algo le molestaba y empezaba, botaba las cosas que mi mamá le brindaba y empezaba ya a maltratarla físicamente, incluyendo a nosotros los hijos. [Entrevista a Tania 2008]
\end{abstract}

La responsabilidad de mantener un estatus en la sociedad, de evitar el qué dirán, o el fracaso frente a la familia también son factores elementales. Ya que la mujer es considerada de la otra familia cuando se casa, por lo tanto el esfuerzo por lograr mantenerse y conseguir su espacio, la obliga a soportar otro tipo de pruebas u obstáculos para ser aceptadas.

Porque por ejemplo a mí varias veces me dieron ganas de venirme para mi casa ya, no, no seguir con eso, con él romper con todo, pero entonces a mí me da pena porque...los papás siempre a uno le han hablado y que piense de tener hijos bueno un poco de cosas y uno no, no, no tuvo en cuenta esas cosas y luego para volver con la hija nuevamente a la casa, bueno se me cruzaban una cantidad de cosas, yo pensé tengo que aguantar como sea, tengo que aprender a convivir con esto y él tomaba muy seguido y así se perdía dos días, tomaba tres veces en la semana y no, no lo dejaba dormir a uno. Pero el cuando estaba bueno él era bien, no, era una persona especial y todo y si, así, pero ya cuando tomaba pues uno ve el cambio de una persona y no lo dejaba dormir no lo reconocía a uno, si muchas cosas creo que, yo hasta mí aspecto físico ¡huy! cambie demasiado, porque yo estaba demacrada, trasnochada y no me dejaba dormir, no podía comer bien, no yo estaba acabada. Mis papas, todo el mundo preguntaba ¿pero a usted que es que le pasa? ¿Por qué esta así? "yo la veo mal" ¿Qué pasa? Me preguntaban pero yo nunca dije nada en mi casa me callaba todo. Entonces uno aprende como a convivir, uno sufre por dentro uno solo, yo nunca le voy a comentar a mi mamá nada, si me aguantaba, ahí es donde a uno le toca derramar muchas lágrimas como mujer $y \ldots$ vivir. $Y$ ya creo que salir de la casa como ahí vivía mi suegra también, pues a veces uno porque esta la suegra porque están los familiares a uno le toca callarse muchas cosas, a uno le toca agachar la cabeza a lo que manden lo que digan y ya hablando con el ya buenos y sanos yo le decía: no... yo no me aguanto estar así, no se, busque alguna solución y creo que el me entendió porque salimos luego a vivir así en otra parte, tuvimos un negocio de una tienda, pero a pesar de vivir así pues fue bueno por un lado porque ya podíamos hablar mejor, ya yo le decía bueno no me gusta esto, la borrachera, por qué toma tanto porque, yo pensé que usted no era así, ya había más dialogo, él a pesar de eso siempre me decía que lo entendiera que si yo lo quería suficiente, que lo tratara de entender, entonces yo le decía que iba a intentar no, porque eso era muy difícil para mí. Pues a veces así cuando estaba bueno el aclaraba muchas cosas por lo mismo yo seguía resistiendo ahí. Por que el con la tienda pues el traía los 
amigos, quería que le destapara cervezas, bueno quería acabar con el negocio, si ahí tuvimos muchas peleas, estuvimos a punto de separarnos ya no daba mas. Si eso es difícil vivir en pareja (Entrevista a Margot Mayo 2008).

Es notorio que hay una permisividad hacia el dominio ya sea porque culturalmente es la sumisión una característica de las mujeres misak o porque hay factores de trascendencia histórica que así lo permiten como son las corrientes de índole religioso tanto católica como protestante. Entonces cuando se pregunto a una mujer por que aguanto tanto maltrato responde:

No porque, por mi Dios, porque si yo lo dejo a él, pues ya teniendo hijos como voy a dejar al marido, por cumplir a Dios, hasta ahora cumplo y hasta la muerte voy a cumplir, por que mi Dios es mi Dios, por que mi Dios nos da la vida, nos ha dado pa criar, nos ha cuidado, nos ha dado el día, nos da la luz y todo lo que trabajamos, él nos bendice y nos da la papa y todo, la cebolla, y por eso yo a mi Dios le agradezco, porque a mi Dios ha hecho los cielos y la tierra, por eso yo creo que mi Dios es grande y poderosos a ese lo creo. (Entrevista a Doña Lucy, marzo de 2008).

Es así como a pesar de que las mujeres tienen una fuerte dominación masculina, ellas han construido mecanismos de resistencia frente a la sociedad patriarcal. Esta resistencia las ha hecho sobresalir en las esferas políticas y sociales del resguardo y mantener su rol milenario de ser inventoras y decisivas en el marco de la familia y en el plano de las actividades productivas. Es decir una mujer Misak es construida como mano de trabajo en la máxima producción tanto de productos agrícolas como de elementos artesanales, lo cual se conjuga con las actividades del hogar.

No se puede llegar a una conclusión determinante respecto a este tema, pero se pueden vislumbrar muchos aportes con respecto al trabajo de la mujer Misak, en el ejercicio de su empoderamiento como mujeres en distintos ámbitos. En pasos siguientes la voz de la mujer Misak seguirá cada vez más fuerte y buscando elementos de resistencia a las dinámicas de globalización y de dominación que sufre. Hasta aquí considero que aunque parezca intrascendente el destino de la mujer Misak, igualmente deben ser sus dinámicas de resistencia y aun más sus transformaciones en la construcción de su feminidad, los que deben considerarse como focos de trabajos a seguir.

\section{Bibliografía}

\section{Fuentes documentales}

Archivo histórico del cabildo de Guambia Silvia Cauca.

Archivo Judicial Centro de Justica de resguardo indígena de Guambia, Silvia Cauca.

\section{Bibliografía}


Beauvoir S. (1949). El segundo sexo. Paría: editorial siglo XX.

Cabral, B. E., y García, C. T. (s.f.). Masculino/Femenino... ¿Y yo? Identidad o Identidades de Género. Documento

Cabral, B. E., y García, C. T. (s.f). Deshaciendo el nudo del genero y la violencia. Otras Miradas, Vol. I, 001.

Castellanos, LI. G., (s.f.). Sexo, Generó y feminismo: tres categorías en pugna. Cali: Universidad del Valle.

Córdova, R. P. (s.f). Reflexiones teórico-metodológicas en torno al estudio de la sexualidad

Kwame A. A. (2007). La ética de la identidad. Buenos Aires: Katz Editores.

Scott J. W. (1990). El género: una categoría útil para el análisis histórico. En Amelang J. and Nash, M (comp). Historia y género: las mujeres en la Europa moderna y contemporánea. Valencia: Edicions Alfons el Magnanim.

Tunubala, G., Taita Dagua A., Galvis, M., y Mosquera, E. (2002-2005). La voz de nuestros mayores" Cabildo Indígena de Guambia. Santiago: editorial López.

Tunubala, G., Taita Dagua A., Galvis, M., y Mosquera, E. (marzo 2007). Espiral de crecimiento y permanencia cultural del pueblo Misak. Plan de vida del pueblo Misak.

Recibido: 5 de abril de 2010. Aprobado: 11 de mayo de 2010. 